\title{
Percepciones sobre la clase en la prensa afrouruguaya (1872-1929)
}

\author{
Perceptions about class in the Afro-Uruguayan \\ PRESS (I872-I929) \\ Mónica García \\ Programa de Posgrado en Estudios Latinoamericanos, \\ Universidad Nacional Autónoma de México \\ monicalatinoamericanos@gmail.com
}

Resumen: Algunas de las formas más recurrentes en la prensa afrodescendiente en el Río de la Plata para referirse a sí misma como colectividad fueron alusiones a la clase obrera. Un recorrido por las publicaciones en el tránsito del siglo XIX hasta las primeras décadas del siglo XX, durante la modernización, muestra el curso que fue tomando la concepción de clase, aunque no necesariamente haya sido explicada de forma explícita.

La idea de clase en el siglo XIX se expresaba en los comentarios sobre todo aquello que implicaba la situación socioeconómica y cultural. Llegado el siglo XX, los periódicos afrouruguayos comenzaron a escribir algunos textos con cierto análisis teórico sobre la clase al mismo tiempo que el movimiento obrero en el Uruguay comenzaba a fortalecerse y las ideas anarquistas y socialistas adquirían difusión. De una u otra forma, la concepción de clase estuvo explicada por condicionantes históricas en conjunción con otras variables como la "raza" o la cultura. En este sentido, la categoría "interseccionalidad" planteada desde el feminismo negro explica cómo dentro del capitalismo se articulan varios regímenes de opresión a la vez. El artículo, por lo tanto, se propone observar, desde los textos de las publi- 
caciones afrouruguayas del periodo 1872-1929, las diferentes perspectivas que tuvieron sobre la clase.

Palabras clave: afrouruguayos, clase obrera, prensa, modernización, afrodescendientes.

Aвstract: Some of the most recurrent forms in the Afro-descendant press in the Río de la Plata to refer to itself as a collectivity were allusions to the working class. A tour of the publications in the transition from the nineteenth century to the first decades of the twentieth century, during modernization, shows the course that the concept of class was taking, although it has not necessarily been explicitly explained.

The idea of class in the nineteenth century was expressed in comments on everything that the socio-economic and cultural situation implied. In the twentieth century, Afro-Uruguayan newspapers began to write some texts with a certain theoretical analysis of class at the same time that the labor movement in Uruguay began to strengthen and anarchist and socialist ideas were gaining diffusion. In one way or another, the conception of class was explained by historical conditions in conjunction with other variables such as "race" or culture. In this sense, the category "intersectionality" raised from black feminism explains how several regimes of oppression are articulated within capitalism at the same time. The article searches in the texts of the Afro-Uruguayan publications of the period 1872-1929, the different perspectives they had on the class.

Keywords: Afro-Uruguayan, working class, press, Afro-descendant, modernization.

\section{INTRODUCCIÓN}

Algunas de las formas más recurrentes en la prensa afrorrioplatense para autodesignarse o para hablar sobre sí misma como colectividad fueron alusiones a la clase obrera. Un recorrido por las publicaciones en el tránsito del siglo XIX hasta las primeras décadas del siglo XX, durante la modernización, muestra el curso que fue tomando la concepción de clase, aunque no necesariamente haya sido explicada de forma explícita. 
En general, fue un concepto polisémico - así como la "raza"1- que podía tanto hacer referencia a la estrechez económica, como a los puestos laborales o la identidad grupal de la población afrodescendiente. Tendrán que pasar algunas décadas para que entrado el siglo XX se le sumara la postura política dentro de la lucha del movimiento obrero en un sentido de clase para sí, como lo apuntara el marxismo ${ }^{2}$.

Términos ligados a "clase" venían siendo utilizados en la prensa afrorrioplatense desde 1858. Una de las primeras publicaciones que se conocen fue El Proletario, de Buenos Aires, bajo la dirección de Lucas Fernández. Otras publicaciones afroporteñas del siglo XIX utilizaron términos relacionados a "clase" en los subtítulos: La Luz (1878), "Órgano de las clases proletarias"; La Broma, a partir de 1880, "Órgano de las clases obreras" y El Unionista (1877-1878), "Órgano de la clase obrera"3. En los periódicos afrouruguayos del siglo XIX el sentido de clase obrera estuvo explícito en los subtítulos de El Periódico y La Propaganda, de la primera época, ambos con el lema "Órgano de las clases obreras".

La idea de clase en las publicaciones afrorrioplatenses del siglo XIX se expresaba en los comentarios sobre todo aquello que implicaba la situación socioeconómica y cultural. A veces, estaba asociada al término "desheredada" o "menos acomodada" (Cirio 47). Otras, era sinónimo de grupo y se utilizaba para la autodesignación de la población afrodescendiente diferenciada del resto de la sociedad uruguaya. Llegado el siglo XX, los periódicos afrouruguayos comenzaron a escribir algunos textos con cierto análisis teórico sobre la clase al mismo tiempo que el movimiento obrero en el Uruguay comenzaba a fortalecerse y las ideas anarquistas y socialistas conseguían difusión.

1 La palabra "raza" lleva comillas en este trabajo por considerarla una categoría que no alude a nada objetivo. Ha quedado demostrada la inexistencia de la subdivisión genética de la especie humana en "razas" distinguibles y separadas unas de otras. Lo que sin embargo existe es la idea de "raza".

2 Para el crítico marxista Georg Lukács el fenómeno tiene que ver con la existencia o ausencia de una consciencia de clase. Cuando la clase es entendida como condición, pero sin ser complejizada políticamente la posición es de clase en sí, y en aquellas instancias o pensamientos en que hay lucha de clase con consciencia de clase se comprende en tanto clase para sí. (Lukács 100-109).

3 Sobre la identificación con la clase obrera en la prensa afroargentina en Buenos Aires, ver el trabajo de Lea Geler, (2010), Andares negros, caminos blancos. Afroporteños. Estado y Nación. Argentina a fines del siglo XIX, Rosario: Prohistoria, pp. 266-274. 
En los relatos de la memoria histórica de su grupo, las publicaciones afrouruguayas tuvieron en la clase una referencia que se extendía hasta sus antecedentes coloniales en el "oscuro" pasado esclavista donde la injusticia y el atraso en que vivían habían sido impuestos a base de maltratos. Continuaba, más tarde, en el papel de los ejércitos y batallones, explicado como su contribución a la formación de la patria, pero con la denuncia de que muchos de sus hombres fueron secuestrados y condenados a las levas forzadas (Andrews 56-58). La población afrodescendiente tuvo una función clave en el proceso independentista uruguayo (Andrews 63) y, más tarde, en la consolidación del Estado, con su participación en las luchas armadas del siglo XIX. El precio fue muy alto. Además de la muerte de parte de su población, deben agregarse otros males como la invalidez para algunos, el maltrato y castigo corporales y el servicio militar forzado, lo que fue denunciado largamente por la prensa afrouruguaya del siglo XIX (Andrews 55-56; Goldman 70-72). Además de las denuncias en su prensa, exiliados afrouruguayos en Buenos Aires, forzados a emigrar por esta causa durante la etapa del militarismo ${ }^{4}$ (Andrews 57), levantaron personalmente un pedido al presidente Máximo Tajes en su visita a Buenos Aires en 1889 (Goldman 70; García 183)5 .

Al llegar al siglo XX, la situación laboral mencionada en las publicaciones dejó de aludir al mundo militar e hizo referencia a los diversos trabajos que no llegaron nunca a la clase media. En esta última etapa la obtención de empleos públicos fue una de las metas procuradas y las publicaciones lo reivindicaron en varias ocasiones.

En este trabajo se expondrán los distintos sentidos que la clase tuvo en las publicaciones afrouruguayas en el curso de las últimas décadas del siglo XIX y las primeras del XX, que corresponden al periodo de la modernización y consolidación del Estado nacional uruguayo, tomando en cuenta la memoria histórica de cómo los afrouruguayos se concibieron a sí mismos como grupo, donde lo "racial", lo cultural y lo socioeconómico se mezclaron en una misma posición. Se entiende,

4 Se conoce como militarismo en el Uruguay al periodo comprendido entre 1874 y 1890 en que el gobierno fue ejercido por militares. Durante el mismo, por medio de un fuerte poder central que controló el país, se consolidó y modernizó el Estado (Nahum 170-215).

5 También Andrews menciona este acontecimiento (Andrews 57), solo que en lugar de referirse al presidente Máximo Tajes, menciona al presidente anterior Máximo Santos, lo cual evidentemente es una confusión en el apellido. 
asimismo, que para los discursos afrouruguayos la clase y la "raza" se articularon de tal forma que, a veces, fluían como sinónimos que definían su situación de opresión. En este sentido, se entiende que desde su punto de vista ambas categorías fueron utilizadas, por momentos, como formas de identificación con la opresión histórica a la que fue sometida la población afrouruguaya. La interseccionalidad, categoría propuesta por el feminismo negro explica esta articulación como un sistema en el que se articulan diferentes regímenes de opresión como el racismo, el capitalismo y el patriarcado ${ }^{6}$.

Los puntos analizados se organizaron en dos etapas que corresponden, por un lado, al siglo XIX y, por el otro, al siglo XX, con un breve apartado intermedio que ubica la acción del movimiento obrero uruguayo y las ideas que circularon en el periodo. Respetando la forma en que la memoria afrouruguaya se ha presentado en sus publicaciones, alcanzando siempre el periodo colonial esclavista en un modo de larga duración, se comienza el artículo con una previa ubicación de los antecedentes coloniales de la población afrouruguaya.

ANTECEDENTES DE LA CLASE OBRERA EN LA POBLACIÓN AFROURUGUAYA

Los antecedentes de la clase en la población afrorrioplatense pueden ser entendidos en la organización colonial de estamentos y regulaciones, con barreras que impedían el ascenso social por medio de normas en la división del trabajo y en las uniones matrimoniales. Por otra parte, los gremios pueden verse como organización obrera embrionaria en tanto se ocuparon de la organización del trabajo entre quienes ejercían los diferentes oficios (Bernand 95-96).

La división del trabajo se afirmaba con las regulaciones del sistema colonial y con otras normas sociales implícitas en la vida cotidiana.

6 Si bien la idea de articular distintas identidades ya había sido utilizada por mujeres afroestadounidenses, fue Kimberlé Crenshaw quien acuñó el concepto de interseccionalidad, que permite explicar cómo diferentes elementos identitarios como la clase, el género y la condición "racial" se entrelazan en la realidad de tal forma que sólo analizándolos en forma entreverada se puede dar cuenta de las diferentes formas de opresión que se articulan en una sociedad específica y en un momento determinado hacia ciertos grupos humanos que en ella viven. 
La vileza, por ejemplo, no implicaba necesariamente una conducta de maldad, sino que poseía el carácter de atributos sociales indeseables. Tal era el juicio hacia quienes desempeñaban trabajos mecánicos o manuales considerados inferiores, que nadie quería hacer y que eran mal considerados moralmente. "Vil" era una palabra comúnmente utilizada para la desvalorización moral de las personas. Por lo tanto, una de las razones por las cuales un africano o africana eran considerados bajos era su trabajo -tareas mecánicas, manuales, pesadas, etcétera, a las cuales se sumaba su condición étnica y su variabilidad física- (Bernand 94). La concepción de trabajo estaba, entonces, atravesada por valores morales que se articulaban con la "raza", aumentando la desvalorización de la población afrodescendiente y, viceversa, el trabajo realizado por afrodescendientes rebajaba el valor de la fuerza de trabajo.

De un modo no radical, el ascenso social y estamental por medio de la unión matrimonial en América también tuvo sus barreras y hubo prohibiciones para algunas de ellas, como las que no permitían el casamiento entre indígenas y africanos. La casta y la variabilidad física constituyeron un impedimento para el ascenso social, tanto para las uniones matrimoniales como para la ocupación laboral (Bernand 99, 107). Las y los africanos y sus descendientes poseían una "marca" visual que delataba la condición de "vileza" que llevaba a la probabilidad de los otros datos: baja condición social, trabajo mal visto, estatus pobre, lazos familiares no deseados por la visión hegemónica, etcétera. Por lo tanto, a partir de las relaciones de la división del trabajo existió una conexión que articulaba el estamento, el gremio y lo "racial". En este sentido, se entiende como interseccional la afirmación de Carmen Bernand de que "la gente de color tiene un triple estigma” (131): por ser casta, por su variabilidad física con una piel más oscura y rasgos africanos y por su labor manual.

Los trabajos a los que se dedicaron fueron variados y asociados principalmente al servicio doméstico y a los servicios de las ciudades como el alumbrado y la recolección de aguas negras. Trabajaron en el servicio doméstico, en la higiene de la ciudad, en actividades portuarias, en la venta ambulante, en las estancias ganaderas, en los saladeros. Fueron lavanderas, nodrizas, planchadoras, costureras, zapateros, sastres, carpinteros, albañiles, herreros, aguateros, fabricantes de velas y, más tarde (1780-1870), trabajadores en la industria saladeril de Montevideo y del interior (Frega et al. 11-12). A esta serie de roles se les agregaron, 
a principios del siglo XIX, las actividades militares de los hombres que fungieron como soldados "carne de cañón" de las tropas que por distintos motivos actuaron durante todo el siglo XIX (Frega et al. 18-19). En las guerras de independencia, primero, y en las luchas civiles, después, los afrouruguayos estuvieron siempre presentes. Este papel les adjudicó a muchos de ellos el estatuto de libertad dentro del sistema esclavista. Más tarde, el Estado nacional siguió necesitando de cuerpos armados durante muchos años; así, una de las formas de ascenso social para los varones afrorrioplatenses fue la incorporación a los ejércitos de los innumerables conflictos armados contra fuerzas extranjeras en la región o en las guerras civiles, durante el largo siglo XIX?

De los sobrevivientes de tales lides se generó un grupo que ascendió socialmente y perteneció al gremio militar. De allí surgieron en el siglo XIX varias de las personas que organizaron asociaciones de la "sociedad de color", con líderes de centros y clubes, y, con ellos, una prensa y opinión pública que hizo de sus impulsores las personas de liderazgo de la población afrodescendiente. Entre las metas que estas organizaciones se propusieron lograr figura que la colectividad saliera de la miseria y que accediera a la instrucción, tanto para capacitar a la juventud como para acabar con el analfabetismo. A causa de este último asunto aplaudían los logros que el Estado uruguayo había conseguido con la implantación de un sistema educativo laico, gratuito y obligatorio desde la reforma de José Pedro Varela.

En gran medida, estas asociaciones de la "sociedad de color" decimonónicas eran continuidades de las organizaciones sociales africanas y afrodescendientes del periodo colonial, como fue el caso de las naciones -conocidas también como salas de nación- y de las cofradías de personas africanas y afrodescendientes esclavizadas y libres que cumplieron funciones sociales similares a las de ayuda mutua, como los servicios funerarios o la asistencia a enfermos (Rosal 600; Goldman 48).

Algunas de las características socioeconómicas que la población afrodescendiente en el Río de la Plata enfrentó en la sociedad colonial

Cfr. Frega, Ana, "La patria me hizo libre: aproximación a la condición de los esclavos durante las guerras de independencia en la Banda Oriental", en Silvia Mallo e Ignacio Telesca (eds.), "Negros de la Patria". Los afrodescendientes en las luchas por la independencia en el antiguo Virreinato del Río de la Plata, pp. 171186, Buenos Aires: SB. 
continuaron procesándose en la nueva estructura moderna del Estado nacional. Sobre todo, porque dicha población siguió reproduciéndose en el escalón más bajo de la pirámide socioeconómica y porque algunas de las labores que desempeñaba en la producción colonial continuaron siendo las mismas, tales como el trabajo doméstico, el cuidado de personas, la mano de obra fabril o el servicio de las armas. Por lo tanto, la relación entre la clase y la población africana y afrodescendiente, así como entre la clase y la variabilidad física, se mantuvo.

Por lo tanto, dentro del concepto moderno de clase social y en sus antecedentes coloniales - de forma compleja pero no inflexible-, entraron diversas variables (cultura, parentesco, ocupación, género, variabilidad física, procedencia, etcétera) que determinaban quiénes tenían más o menos recursos y más o menos prestigio. Los periódicos afrouruguayos dejaron registro de las condicionantes y barreras que el Estado nacional uruguayo ejerció contra la población que representaba, demostrando que la igualdad quedaba en los papeles de la Constitución y que la injusticia continuaba de todos modos, luego de haberse acabado el periodo colonial y esclavista.

\section{LAS PUbliCACIONES AFROURUGUAYAS DEL SIGLO XIX Y PRIMER AÑo DEL XX $X^{8}$}

Las publicaciones afrouruguayas del siglo XIX tenían explicaciones sobre la situación de marginalidad que ocupaban dentro de la sociedad, donde las causales eran condicionantes impuestas o consecuencias de ello. Aunque no hiciesen propaganda sindical, su pertenencia a la clase trabajadora estuvo siempre presente y permanentemente asociada a la de

8 Con el objeto de entender mejor el mundo periodístico afrouruguayo, a seguir, se presentan algunos datos básicos de las publicaciones analizadas: La Conservación, 1872-73. Fue el primero de los periódicos afrouruguayos. Salió a la arena periodística en septiembre de 1872 y circuló hasta noviembre de ese mismo ańo, llegando hasta el número diecisiete. Fue fundado por Andrés Seco y Marcos Padín. El Progresista, 1873-74. Apareció el 4 de septiembre de 1873 y funcionó hasta el 16 de octubre de 1873 , con una producción de siete números en total. Fue una continuación de La Conservación y conservó los mismos directores: Marcos Padín y Andrés Seco. La Regeneración, 1884-85, en su segunda época estuvo bajo la dirección de Enrique Munn y Manuel Aturahola. Circuló desde 
"raza". Como lo analiza George Andrews en Negros en la nación blanca, esta asociación entre ambos conceptos deriva de que la mayor parte de la población afrouruguaya era trabajadora (Andrews 61).

Sobre el estatus colonial, comentaban que la situación socioeconómica y el atraso en la baja o nula instrucción tenían su causal en el crimen del "blanco" sobre ellos en el régimen esclavista (Andrews 60). Es decir, la esclavitud en la que habían sido injustamente deshumanizados no se debía a la naturaleza de la variabilidad física o a aspectos culturales, sino a la imposición de la violencia de un grupo - "los amos, los blancos"- sobre ellos, los llamados "negros". Por lo tanto, la clase y la "raza" tenían condicionantes históricas. Los periódicos de la comunidad hicieron alusión innúmeras veces al tratamiento inhumano sobre su grupo, con el que impusieron la condición social. El artículo sin autor "Una ojeada sobre nuestra sociedad" de La Conservación en 1872 afirmaba": "Que se concluyeron aquellos tiempos que tenian á nuestros padres sumisos á sus mandatos, que con una palabra los intimidaban. Que concluyeron aquellos tiempos de barbarie en que cualquiera dándose aires de "mandon" solo manejaba el látigo para esos

el 14 de diciembre de 1883 hasta el 26 de abril de 1885, llegando hasta el número veintiuno. El Periódico, 1889, circuló desde el 5 de mayo de 1889 al 8 de septiembre de 1889, alcanzando los diecinueve números. Sus directores, Felipe Pereyra e Hipólito Martínez presentaron la publicación como "órgano de las clases obreras". La Propaganda de la primera época, 1893-94, apareció por primera vez el 3 de septiembre de 1893 y circuló hasta el 3 de febrero de 1895 bajó la administración de Juan G. Núńez y José B. Acosta. Salió sin interrupciones todos los domingos de cada mes, alcanzando los setenta y cinco números.El Eco del Porvenir, 1901, salió a la luz el 25 de agosto de 1901. Su existencia fue muy corta. En los archivos llega hasta el número 4. Sus fundadores fueron el músico afroargentino Guillermo Céspedes y Brígido Sosa Anaya. La Propaganda de la segunda época, 1911-12, apareció el 10 de mayo de 1911 y llegó a su fin el 12 de abril de 1912, alcanzando los treinta y un números. Su edición se organizó a partir de la sociedad civil Agrupación Pro-Centro. Sus directores fueron Pedro O. Pérez y Marcelino Bottaro. La Verdad apareció el 15 de septiembre de 1911 y acabó el 31 de julio de 1914. Salía tres veces al mes, los días 5, 15 y 25. Tuvo varias personas en su dirección, entre ellos, Elemo Gilberto Cabral y entre los administradores Benigno Machado, Alfredo Silva y Lino Suárez Peña. La Vanguardia comenzó el 15 de enero de 1928 y llegó hasta el 15 de marzo de 1929, con el número veintinueve. Fue fundado por el abogado afrouruguayo Salvador Betervide y por Isabelino José Gares.

9 Las citas se presentan textuales para mejor comprensión de los textos. 
infelices"10. Es decir, el atraso de su grupo no era algo natural de las personas de "color", sino logrado a base del maltrato sicológico y físico: "Pero lo mas lamentable era el tratamiento que se usaba con aquellos infelices, tratamiento que no se borrara jamas de nuestra memoria"11.

Por lo mismo, la vergüenza del estatus de esclavitud debía llegarle no a su grupo, sino a los opresores y sus descendientes: "Es mancha acaso que nuestros padres, hayan sido esclavos? Contesten los que han sido sus opresores, si el baldón cae sobre el asesino ó sobre la víctima. Contesten si es mancha para nosotros, el que nuestros padres hayan sido arrancados de su patria, y negociado como una vil mercancía" ("Nuestro candidato" 1), preguntaban los afrodescendientes desde la prensa.

Las denuncias hacia las levas forzadas, ya mencionadas, para los varones afrouruguayos fue otra constante en las páginas de las publicaciones y venía acompañada de la explicación de que había barreras para ascender en el ejército uruguayo, aunque la experiencia y el desempeño de sus miembros afrodescendientes hubieran sido intachables: “¿Por qué un soldado de color, aunque permanezca veinte ó mas años en un batallón, jamás es nombrado, no pongamos otro grado pero ni alférez? ¿Y porqué el blanco, por que es hijo del Dr. Tal, no bien pone los pies en el cuartel y ya lo tenemos plantado de capitán?” ("Los derechos" 1).

El Progresista, en 1873, también aclaraba otro punto: según las leyes, estaba permitido retener a quienes se les había suspendido la ciudadanía porque habían cometido delitos. Los redactores se preguntaban si acaso "¿Todos los hombres de color que están en servicio activo, están suspendidos de la ciudadanía?" ("Igualdad ante la ley" 1).

El atraso o ascenso también estaba condicionado por el grado de educación. El Progresista denunciaba la falta de instrucción en la campańa y que, debido a ello, los buenos puestos los ocupaban los inmigrantes que ya venían preparados, dejando atrás a su población en la posibilidad de ascenso social: "En nuestra campaña son la mayor parte jóvenes estranjeros pues como estos vienen instruidos de su patria son aptos para esos puestos lo que no sucede con nuestros hijos" ("Las escuelas de campaña" 1).

10 "Una ojeada sobre nuestra sociedad", La Conservación, Montevideo, número 1, 4 de agosto de 1872, p. 2.

11 “Ayer y hoy", La Conservación, Montevideo, número 4, 27 de octubre 1872, p. 1. 
El Progresista tenía claro que la división de clases fue impuesta en la colonia para ejercer el dominio de la población: "Comprendiendo que la bárbara división de las clases, [fue] implantada por los déspotas para embrutecer al pueblo y gobernarlo". El artículo "Adelante" explicaba que el sistema de castas fue el régimen que convirtió su origen africano tanto cultural como corporal en la clase desheredada que vivían en su presente y que el régimen republicano era la oportunidad para acabar con la desigualdad: "Demostrar que la desigualdad de castas, idea hija natural de la ignoracia ó de un estravio censurable, solo aprovecha á las monarquias, que únicamente puede existir sobre la humillación, y el servilismo" ("Adelante” 1).

Años después, El Periódico. Órgano de las clases obreras (1889) añadía un punto más, asociado a las nuevas medidas de la modernización para imponer el disciplinamiento de la campańa: el combate a la vagancia fue utilizado como pretexto para retener hombres. La publicación denunciaba que muchos hombres de su grupo eran secuestrados en las zonas rurales bajo el rótulo de "vagos" y conducidos a los cuarteles de Montevideo. Para El Periódico, el atentado era hecho contra la clase trabajadora: "La remesa que ya consignada llega de la campaña, viene con el rótulo de Vago, y con este pase aumenta los cuerpos de guarnición [...] Con nombres propios denuncia la prensa de campaña y transcribe ésta de la Capital las arbitrariedades y escándalos que se cometen con la clase trabajadora á pretexto de engrosar el ejército" ("Las escuelas de campaña” 1).

La Regeneración de la segunda época (1884-1885) hizo referencia a condicionantes de la clase aludiendo al proletariado (Andrews 61) y de forma reiterada publicó crónicas de la vida social muy vinculada con la corporación militar. Trasmitió noticias sociales de militares afrodescendientes como la referente al recibimiento de medallas por su participación en la guerra de la Triple Alianza en el Paraguay y también publicó textos recordando fechas de batallas. Su posición era la de un grupo en mejores condiciones económicas y de constante conexión con la colectividad afroargentina. La publicación, sin anuncios, con subvención económica, indicaba mayor estatus. Además, parecía apoyar el gobierno militar del momento. Asimismo, dio a entender que existía persecución hacia los hombres afrodescendientes en el Uruguay para remitirlos a las levas, a diferencia de la Argentina que 
no lo hacía. Consideraba la prensa un medio fundamental de educación y, en ello, el periódico jugaba un papel protagónico, un medio de opinión y denuncia que su grupo debía utilizar porque es "el que más contiene los abusos del fuerte contra nuestro perseguido color" ("No es obra de romanos" 1).

Finalizando el siglo, La Propaganda, de la primera época "Órgano de las clases obreras" (1893-95), también se refirió a la clase como a la situación socioeconómica, con énfasis en los bajos recursos económicos y educativos, así como a la necesidad de preparar a la juventud de su colectividad para una mejor posición, no igual a la de sus padres, sino mejor y denunció, como las anteriores publicaciones, las levas forzadas hacia sus varones. Una de las menciones a su pertenencia a la clase obrera se encuentra al momento del fallecimiento de Plácido Ellauri, quien fuera profesor en la Facultad de Derecho ${ }^{12}$ y muy querido por el alumnado. Un articulista de $L a$ Propaganda demostraba su admiración hacia el maestro y se menciona a sí mismo como alumno perteneciente a "las clases obreras", que recibían el apoyo del profesor: "La Propaganda como órgano de las clases obreras á las que nunca les negó el extinto el apoyo y sus sanos consejos, se inclina con respecto ante la tumba del ilustre maestro pidiendo la paz para su alma" ("El doctor don Plácido" 1). Un detalle valioso es que, por lo menos, hay un redactor de la publicación que para 1893 frecuentaba las aulas universitarias, lo cual concuerda con los estudios del primer abogado afrouruguayo que logró vivir de su profesión: Francisco Rondeau, titulado en $1894^{13}$. La Propaganda de la época daba la noticia reproduciendo una nota del diario El Siglo (“El Señor Francisco” 1-2).

El artículo "Soldados a la fuerza" denunciaba los secuestros de los varones para las levas forzadas (Andrews 59) y la clase, asociada a la variabilidad física, estaba implícita en ese abuso. El artículo denunciaba que las levas existían para los varones de la "sociedad de color" aun imperando una constitución de por medio que establecía igualdades.

12 Según Arturo Ardao, Ellauri junto con De la Peña fueron los responsables de que existiera el eclecticismo filosófico (positivismo y espiritualismo) (Ardao 49), exactamente hasta el arribo del militarismo en el cual asumirá su imperio el positivismo (Ardao 50).

13 El primer abogado afrouruguayo fue Crisóstomo Díaz, quien no pudo ejercer su profesión (“Doctor Crisóstomo Díaz” 1). 
Cada denuncia hecha incluía un relato individual en la cual la víctima estaba siempre en situación de pobreza económica.

La Propaganda se afirmó en su lema de "órgano de las clases obreras" y explicaba su función de cohesión de la colectividad haciendo una retrospectiva de su trabajo: "Declarándose La Propaganda órgano de las clases obreras creyó desempeñar mejor los intereses de la comunidad. Sin humillaciones, sin rebajar la condicion de hombres libres [...] Hemos bregado por la unión de la colectividad, dedicando sucesivos artículos, porque vemos que en ella se encierra la base de nuestra prosperidad" (“Agradecemos" 2). La expresión "hombres libres" utilizada llama la atención. Que un afrouruguayo en 1894 diga que es hombre libre y además asociado a la pertenencia de clase obrera, induce a pensar que ser clase obrera fue un nuevo paso en el proceso socioeconómico y cultural de la población afrouruguaya luego de adquirir el estatus de personas libres, a partir de la abolición definitiva de la esclavitud. La clase había roto con la casta, aunque no con las inequidades.

En el tránsito al siglo XX, El Eco del Porvenir (1901) en sus escasos números, no hizo referencias al tema de la clase, pero sí nombró en varias ocasiones el papel en los ejércitos de algunos de sus integrantes, una generación que participó en varios sucesos en el campo de batalla y que tenía relaciones con grandes militares como Bartolomé Mitre. La forma de referirse a la pertenencia al ejército de varios de sus miembros fue completamente diferente al tono utilizado por las demás publicaciones y no hacía referencia a las levas forzadas. El papel desempeñado en el ejército, según lo expresaba El Eco del Porvenir, era bien visto y gozaba de estatus, a diferencia de las denuncias de pobreza y secuestro de las levas forzadas, en las cuales los soldados son presentados como presos que cuando lograban salir de los batallones continuaban con su bajo rango, sin posibilidades de ascenso dentro de la corporación. Lo que demuestra que, a fines del siglo XIX y principios del XX, el papel militar de la población afrouruguaya a nivel interno tuvo distintos matices sociales, que tenían en común la resignificación de su participación meritoria en la fundación de la nación uruguaya a pocos años de acabado el régimen esclavista ${ }^{14}$ : "No hace quizá un cuarto de siglo,

14 La abolición de la esclavitud en el Uruguay, como en el resto de América Latina, fue un proceso gradual. En el Uruguay se concretó principalmente dentro de la Guerra Grande (1839-1851). Se considera la fecha oficial de su declaración 
en que nuestros hombres arrebatados de la labor continua del trabajo, para esgrimir la lanza en defensa de las peligrosas aventuras de su suelo patrio, y privados de la libertad que la Constitución y las leyes acuerdan; se veían obligados a permanecer reacios ante el indiferentismo de tales consecuencias" (“Antes y Ahora” 1).

La falta de instrucción de su población era puesta como causante: "Creemos no equivocarnos si decimos que la mayor parte que la compone entre nosotros carece del pan bendito de la instrucción" ("Instrucción I" 1). El grado de analfabetismo de la colectividad provenía de la imposibilidad o descuido de los padres, aunque hubiesen cambiado los tiempos y pudiesen alfabetizarse en la adultez. La alfabetización, además de ser una puerta para el ascenso social, evitaba que las nuevas generaciones cayesen en la delincuencia: "Sabido es que hasta para simple portero de una oficina del Estado se requieren aquellas cualidades" (ibid.). La labor de portero en oficinas públicas era uno de los mejores trabajos a los que podían aspirar; varios integrantes de la colectividad se dedicaban a ello.

Por lo que dentro de la clase hay que tomar en cuenta la diferencia interna entre los afrouruguayos, claramente observable entre quienes participaron en los ejércitos: aquellos que hicieron carrera militar y lograron el ascenso social individual y aquellos que no tuvieron ascenso $y$, por el contrario, les fue truncada durante años, o para siempre, la posibilidad de buscar opciones de mejoramiento por otros medios. Otra diferencia estuvo en el acceso a instrucción: por un lado, el alto índice de analfabetismo dentro de la población afrouruguaya y, por el otro, el grupo intelectual que producía los periódicos que no excluía a algún redactor que frecuentaba el mundo universitario.

Algunas tareas de la época esclavista seguían siendo las mismas, las mujeres trabajaban, como antes, en el servicio doméstico, como puede

en 1842. Sin embargo, en el territorio uruguayo hubo personas esclavizadas hasta 1860. Al norte del Río Negro, donde muchas tierras eran propiedad de brasileros, el fin de la esclavitud se retardó. Sobre el tema ver, entre otros, los trabajos Abolicionismo y tráfico de esclavos en Montevideo tras la fundación republicana, 1829-1853 (2009) de Alex Borucki y "Abolición y esclavitud en el Estado Oriental del Uruguay, 1830-1860” (2010) de Alex Borucki, Karla Chagas y Natalia Stalla, en Silvia Mallo e Ignacio Telesca (coord.), "Negros de la patria": los afrodescendientes en las luchas por la independencia en el antiguo Virreinato del Rio de la Plata (2010), pp. 211-228, Buenos Aires: SB. 
verse en anuncios y comentarios sociales ${ }^{15}$. Una labor llevada a cabo por afrodescendientes desde el periodo colonial fue mencionada por El Eco del Porvernir: la de cochero (Bernand 87). Manuel Aturahola, activo participante de la colectividad, redactor en periódicos y administrador de La Regeneración (1884-1885), fue designado en 1901 para un cargo en el gremio de cocheros: "En la noche del 30 del pasado, tuvo lugar una reunión del gremio 'Conductores de Vehículos' con el objeto de constituir una sociedad protectora, á la que concurrió un gran número de afiliados. Se nombraron cinco tesoreros delegados, recayendo el cargo de Depositario General en la persona de nuestro amigo Manuel Aturahola" ("Noticias" 4).

Por lo tanto, la clase con origen en el periodo colonial era una posición formada históricamente por factores externos que había que cambiar de forma individual o colectivamente utilizando los fundamentos que eran la base en que se había fundado el Estado. El aspecto moral no debe olvidarse: el tratamiento sobre la vileza bajo las regulaciones coloniales se reproducía en la república con otras formas de ofensas, desprecios y violencias.

La tendencia hacia una conciencia de clase por parte de personas de la colectividad aparecerá en el siglo XX.

\section{EL MOVIMIENTO OBRERO EN LAS PRIMERAS DÉCADAS DEL XX}

A fines del siglo XIX, el Uruguay se encontraba con un movimiento obrero incipiente, que crecía en ideas y acciones. Entre ellas, la lucha contra el sistema capitalista enarbolada por grupos anarquistas y socialistas marxistas, o una mezcla de ambos.

En el amanecer del novecientos, la inmigración proveniente principalmente de Europa aumentó y surgió el auge de las asociaciones y centros culturales que congregaban seguidores de diferentes corrientes provenientes de una Europa proletarizada, que había empezado a organizarse como clase obrera. El campo intelectual y estético también había

15 Si bien las publicaciones reiteraron su condición de clase desheredada y las casi nulas posibilidades de ascenso laboral, no acostumbraron a comparar sus puestos laborales con los trabajos que realizaban sus antepasados durante el régimen esclavista. 
cambiado en el comienzo del siglo y una nueva generación de escritores, conocida como Generación del Novecientos ${ }^{16}$, arribó a la arena literario-filosófica que pensó lo nacional dentro de lo continental. Entre la fértil producción de obras, el Ariel de Rodó -escritor tantas veces citado por los periódicos afrouruguayos-, publicado en 1900, iniciará el siglo con una nueva perspectiva que influyó en el pensamiento uruguayo y latinoamericano de forma determinante (Zum Felde 59).

El anarcosindicalismo nacía y comenzaba a emprender varias acciones. Entre ellas las fundaciones de: la primera gremial de los obreros tipográficos en 1870, la sección de la Asociación Internacional de Trabajadores (A.I.T.) o Primera Internacional de los Trabajadores en 1872 y en 1875 la Federación Obrera Regional Uruguaya (FORU) (Tarcus 257). A estas fundaciones les siguieron las primeras huelgas, sangrientas y criminalizadas, antes de finalizado el siglo (Muñoz 10).

En los primeros años del siglo XX hubo grandes cambios. Se obtuvieron logros importantes como la jornada laboral de ocho horas, la extensión de la jubilación para gran número de trabajadores, la formación de sindicatos, el derecho a la huelga, etcétera (Rama 106). La universidad y los espacios críticos dejaron atrás a los intelectuales de "torres de marfil del 1900" para producir intelectuales comprometidos (Rama 71). Fue el momento, en el sentido gramsciano, de la acción de los intelectuales orgánicos y de una mayor hegemonía del Estado uruguayo con el surgimiento del batllismo ${ }^{17}$ y su política de buena relación con la clase trabajadora (Zubillaga y Balbis 152-154).

Se conoce como Generación del Novecientos a un grupo de destacados escritores que incursionaron en un estilo literario, en gran parte, modernista. Los principales autores fueron José Enrique Rodó, Javier de Viana, Carlos Reyles, Horacio Quiroga, Carlos Vaz Ferreira, Delmira Agustini, María Eugenia Vaz Ferreira, Florencio Sánchez y Julio Herrera y Reissig, Con excepción de Carlos Vaz Ferreira, ninguno fue universitario. Para Zum Felde, un vacío existencial marcó la generación intelectual uruguaya del momento: "época de escepticismo general nunca igualado", "derrumbe de toda arquitectura espiritual", "todas las creencias religiosas se hallaban postradas" (10), de "vacíos metafísicos, voceros de una época marcada por la decadencia (13).

17 El batllismo en sus primeras épocas (primera mitad del siglo XX) fue una corriente política liberal reformista, en la que el Estado tendía a comportarse como benefactor. Generada a partir de las ideas y acción del dos veces presidente de la república y fundador del diario El Día, José Batlle y Ordóñez. 
Con la reelección de Batlle y Ordónez en 1911, el socialismo consiguió en la asamblea legislativa una banca representativa, ocupada por el abogado Emilio Frugoni. Después de varias huelgas de distintos gremios de forma separada, el movimiento llegó a la primera huelga general el 25 de mayo de 1911, que contó con la participación de un número importante de trabajadores (Muñoz 50).

La primera huelga coincidió con la existencia de la publicación afrouruguaya $L a$ Propaganda de la segunda época, la cual hizo una mención sobre el acontecimiento. Aclaraba que el atraso en la salida del periódico fue debido a la huelga. Manifestó que "no juzgaría los hechos", lo cual la colocaba en una posición de neutralidad que no permite distinguir si estaban a favor o en contra, o si hubo, tal vez, una separación entre las opiniones.

La FORU no pudo mantener su dirección ideológica y se dieron debates fuertes entre anarquistas y socialistas comenzando el giro hacia el comunismo, influidos principalmente por la Revolución Rusa, que trajo cambios al interior del movimiento obrero y por lo cual se desarticularía, finalmente, la FORU (Muñoz 81).

A fines de la década del veinte ocurrieron en el Río de la Plata dos eventos internacionales del movimiento obrero de gran importancia: el Primer Encuentro de la Confederación de Sindicatos Laborales Latinoamericanos, realizado en Montevideo en mayo de 1929, y la Primera Conferencia Comunista Latinoamericana en Buenos Aires. Algunas exposiciones abordaron el cruce de la clase con factores "raciales". Las delegaciones de F. Blanco de Bolivia y la enviada por el peruano José Carlos Mariátegui hacían referencia a la situación de miseria y explotación de los pueblos originarios de América Latina ${ }^{18}$.

Blanco observaba que la población indígena era mayoría en México, Guatemala, Bolivia, Ecuador y Perú; rechazaba la visión burguesa que la colocaba como un problema administrativo, consideraba que el problema era económico y humano y que los indígenas sufrían de una explotación bárbara que los constituía en una masa aliada "natural" a la organización proletaria ("Undécima sesión" 67). Mariátegui, por su parte, afirmado en su socialismo latinoamericano envió una propuesta que se tornó histórica y ponía sobre la mesa el análisis del "problema indígena”. Para el pensador marxista, la clase era una cuestión que tenía particularidades históricas propias y no se podía continuar con las acciones del movimiento obrero mundial ignorando las necesidades y problemáticas específicas de los indígenas (18-23). 
Otra propuesta que relacionaba la clase con lo "racial" fue planteada por el líder afrocubano Sandalio Junco, quien incluyó el racismo hacia los afrodescendientes del continente dentro de los problemas de la clase trabajadora en la ponencia "El problema de la raza negra y el movimiento proletario" ("Duodécima sesión" 69). Junco denunciaba el racismo hacia los trabajadores afrodescendientes y señalaba la similitud de posiciones con los indígenas, ya que la problemática indígena señalada por los compañeros tenía las mismas raíces que la que tenían los afrodescendientes: "Tiene este problema muchos significados con el de los indígenas. La negra y la indígena son dos razas igualmente oprimidas y humilladas por el capitalismo y los dos grandes sectores que han formado el grueso del proletariado continental" (Junco 160). A seguir, Junco historizaba la trata y la esclavitud como consecuencia del exterminio que en el Caribe sufriera la población originaria. Denunciaba el racismo que afectaba a dicha población porque se la excluía de espacios y recursos, de lugares donde no se le permitía entrar, se la condenaba a la segregación racista en Estados Unidos, padecía bajo "el moderno tráfico de esclavos hecho por empresas imperialistas del Caribe y de la red de explotación de trabajadores" (Junco 165), donde los afrodescendientes eran los que llevaban la peor parte, porque las condiciones laborales eran inferiores, lo cual era válido para afrodescendientes de todo el continente, ya que existían, incluso, en el Uruguay, como acababa de ver (Junco 162).

Pasados los dos grandes encuentros, el de Montevideo y el de Buenos Aires, el antiimperialismo traería nuevas ocupaciones y protestas desde el movimiento obrero latinoamericano en apoyo a los países centroamericanos, a los que se adhirió el grupo afrouruguayo en torno a la publicación La Vanguardia.

Las publicaciones afrouruguayas de las primeras décadas del siglo XX, luego de El Eco del Porvenir, en mayor o menor medida, dan testimonio de la percepción sobre la clase, la cual fue transitando hacia nuevos significados por el peso de las acciones e ideas que promovía el movimiento obrero.

\section{LAS PUbliCACIONES EN LAS PRIMERAS DÉCADAS DEL SIGLO XX}

Las explicaciones y referencias continuaron similares a las del periodo anterior con la gran diferencia que ya no hubo mención a las levas forzadas. Las descripciones sobre la condición de clase que hicieron 
las publicaciones a principios del siglo XX abordaron la situación económica, el analfabetismo y el mundo del trabajo, con comentarios sobre puestos laborales y la lucha por ascensos a trabajos públicos. $\mathrm{Al}$ llegar a La Vanguardia (1928-29) se aprecia un mayor intercambio con personas no afrodescendientes que apoyaban el internacionalismo. De las decenas de miles de personas que arribaron al Uruguay en este periodo, algunas de ellas compartieron los mismos espacios laborales y de vivienda con los afrouruguayos en conventillos, casas de inquilinato y barrios.

Por otra parte, es importante seńalar que las opiniones y acciones de las personas en torno a los periódicos no significaba de modo alguno que las y los afrodescendientes del Uruguay, en su heterogeneidad, pensasen lo mismo. Esta situación puede observarse, por ejemplo, en las manifestaciones y marchas políticas, donde-como puede verse en fotografías de la época- había personas afrouruguayas tanto entre las manifestantes cuanto del lado de la represión policial -labor que continuaba su papel histórico de servicio en las tropas-.

En La Verdad, el artículo "El derecho á vivir" del redactor de seudónimo Davit, que escribió varios artículos en La Verdad y mantuvo disputas con el cuerpo editorial de La Propaganda de la segunda época, denuncia la explotación de la clase trabajadora con una interesante explicación de las ideas darwinistas. El artículo redactado en la misma línea que lo hacían las propuestas de la clase obrera, aseveraba que existía un discurso de la clase dominante que, apoyado en una interpretación oportunista de las teorías de evolución de Charles Darwin, justificaba la explotación de la clase trabajadora por medio de "una interpretación parcial de la teoría darwiniana llamada lucha por la existencia, que afirma que "los fuertes y los inteligentes vencen y suprimen á los débiles y mal dotados" (Davit, "El derecho" 1). El artículo de Davit no criticaba a Charles Darwin, sino a los "oportunistas" que tomaban sus ideas para utilizarlas a su favor e inventar una supuesta inferiorización humana. Se percibe, por otra parte, la familiaridad con que se entiende la idea de inventar verdades para justificar actitudes. Desde siempre la colectividad había luchado por una igualdad dada como verdadera y real, que a la hora de su aplicación nunca llegaba. El texto de Davit explica la desigualdad con la idea de clase, pero adaptable a la de "raza" en tanto la ciencia daba elementos para justificar una supuesta inferioridad biológica. Tanto en el racismo como en la 
sociedad de clases existía un robo hacia la humanidad de esas personas, explicado con la idea de inferioridad natural. A esas personas, Darwin les había venido como anillo al dedo. La cita a seguir es larga, pero necesaria por su elocuencia:

\section{El derecho á vivir}

El concepto de la vida plácidamente disipada en un banquete donde no hay puesto para todos los vivientes y del que han de ser arrojados como intrusos los que al nacer no tienen en él cubierto preparado, era insuficiente para satisfacer la conciencia de los beneficiados y más insuficiente aun para acallar las protestas de los que, sintiendo en sí la inmanencia de un derecho que compartían por igual con todos los humanos, y con fé mas intuitiva que consciente en una sociedad racional y científica, recurrían á la difusión de ideales más verdaderos y justos. Necesitábase, pues, un complemento, y éste no tardó en presentarse, suministrado por una interpretación parcial de la teoría darwiniana llamada la lucha por la existencia, que afirma que "los fuertes y los inteligentes vencen y suprimen á los débiles y mal dotados". Bastaba con eso para que los comensales del privilegio se juzgaran fuertes é inteligentes, y ya no vieron hombres, sino inferiores, en los arquitectos y obreros que trazan y edifican sus palacios, en los artistas artesanos que los cubren de cuadros, muebles y utensilios, en los servidores que les asisten, limpian y ceban, en los trabajadores de la agricultura, de la industria del transporte, que cultivan, cazan, pescan, fabrican y transportan, para que nada les falte de lo qe necesitan, con necesidad verdadera ó ficticia, en los artistas científicos, jurisconsultos, sacerdotes, gobernantes y gendarmes que les recrean, cura, defienden su derecho legal aseguran su felicidad eterna, ejercen el poder en su beneficio matan ó se hacen matar por ellos (ibid.).

El artículo explicaba que estas interpretaciones semiparciales de la teoría de la lucha por la sobrevivencia no tenían interés en atender a la otra parte de la teoría de Darwin, quien proponía una especie de compensación y que para ello defendía la existencia de "comunidades que, gracias á la unión de gran número de individuos, prospera admirablemente y llevan á buen término la más rica progenitura" (ibid.). 
El texto demuestra que la intelectualidad afrouruguaya había avanzado en la creación literaria y analítica y que tenía puntos de encuentro con los discursos de la clase obrera. Por ejemplo, la alusión a la clase dominante asociada a comilonas, banquetes y comensales: "El concepto de la vida plácidamente disipada en un banquete donde no hay puesto para todos los vivientes" o "Bastaba con eso para que los comensales del privilegio se juzgaran fuertes é inteligentes" (ibid.). Los discursos se acercaron, en ocasiones, al anarquismo. El artículo arriba, por ejemplo, directamente menciona a los pensadores anarquistas Piotr Kropotkin y Élisée Reclus, quienes constituían para el articulista un par de excepciones dentro de una mayoría de "servidores de la adinerada burguesía": "Quedan la veintena de sabios que dogmatizan en nombre de la ciencia y del orden social, y éstos, aparte de algunos contadísimos, que como Kropotkine y Reclus, llevan la lógica científica á sus últimas consecuencias, se convierten en servidores de la adinerada burguesía" (ibid.).

La Verdad publicó un artículo sobre uno de los pilares anarquistas: la solidaridad. El texto también de Davit aludía al origen de la organización solidaria que estaría en el clan y que de allí se había hecho imprescindible la organización colectiva para compensar la insuficiencia de cada individualidad. El lenguaje utilizado nuevamente es similar al de los discursos obreros: "Lo positivo es que ni aquellos comunistas eran perfectos solidarios, por cuanto tenían por esencial enemigo al extranjero, ni estos burgueses son excesivamente egoístas, ya que dan todo, aunque sea por dinero y con sujeción á los precios de tarifa ó á las oscilaciones de la oferta, la demanda" (Davit, "La Solidaridad" 2).

Sobre la clase se adhería a la trabajadora con varios textos y comentarios. En su primer número, por ejemplo, transcribía un artículo del escritor y periodista uruguayo Daniel Herrera y Thode que mostraba la realidad del canillita, el voceador de diarios ${ }^{19}$. El artículo visibiliza la desprotección y falta de derechos laborales de estos trabajadores, niños en muchos casos, "que más de una vez habrán soñado ser pájaros", que no tenían garantías de nada, teniendo en cuenta que formaban parte del proceso de producción de una empresa que se beneficiaba con su trabajo y lo único que recibían eran unas capitas para el frío y

19 El término "canillita" se utilizaba para referirse al voceador de diarios, muchas veces, niño. 
la lluvia (Herrera y Thode 4). La Vanguardia apelaba a los legisladores que tanto pregonaban la democracia al concretar leyes de amparo que "obligue[n] a los industriales de nuestra prensa a reconocer que nadie, con más bien ganados títulos que el pobre 'canillita', tiene derechos legítimos para participar en las ganancias, generalmente considerables, de esas empresas que se enriquecen gracias a la actividad dinámica de ese mismo canillita" (ibid.).

El racismo hacia la clase trabajadora afrodescendiente antillana, en una intersección entre la clase y la "raza", fue puesto en evidencia por medio de la transcripción de un artículo del escritor socialista español Luis Araquistáin: "Si no fuera por los negros, desaparecidos los indios de la economía de estos países del trópico, difícilmente hubiera logrado su esplendor actual. La imponente fábrica de la riqueza antillana se yergue sobre columnas de bronce humano" ("De Luis..." 4). La descripción coincide con la denuncia que el sindicalista afrocubano Sandalio Junco realizaría al ańo siguiente en los dos encuentros obreros latinoamericanos de Montevideo y de Buenos Aires citados arriba.

El antimperialismo fue parte de la plataforma ideológica de $L a$ Vanguardia, un punto que se compartía con las reivindicaciones del movimiento obrero uruguayo y latinoamericano (Melgar 232). El imperialismo se destapó aún más ante la invasión de Nicaragua por parte de los Estados Unidos. En el artículo, el imperialismo era tan condenable como lo era su racismo y ambas violencias eran vistas como producto del mismo sistema opresivo, que

en un imperialismo desalmado, manoseó a México, a Cuba y extendió su gesto amenazador, su mirada de buitre, por toda América. [...] Pero el último zarpazo de la fiera nos hizo recordar los arańones que aún no han cicatrizado en nuestra piel. Los Estados Unidos de Norte América ensanchando su campo de acción imperialista han clavado sobre la indefensa república latina de Nicaragua sus garras leoninas. ¡Estamos frente a lo inaguantable! ¡Somos americanos de la América Latina! ¡No podemos callarnos! ("Panamericanismo" 1).

La Vanguardia rechazaba al país del norte por varios motivos y en su lógica nuevamente se observa la interseccionalidad de dos formas de opresión: el racismo y el imperialismo. Aliado al antiimperialismo, el 
grupo en torno a La Vanguardia tomaba una postura latinoamericanista que será una constante en las futuras publicaciones de la colectividad.

Interesante también fue la forma cooperativista propuesta para el funcionamiento de la publicación por sus creadores ante la asamblea que votó su aparición. Allí, sus iniciadores dejaban claro que, dada la falta de recursos de sus integrantes para la marcha de tamaña empresa, consideraban que probablemente "en la vida moderna sea el cooperativismo el más fuerte sostén de todo esfuerzo gestado en la formidable justiciera vida democrática”. ("Realización” 2). La elección de un sistema opuesto a la lógica de ganancia capitalista, o a la subvención de algún capital privado, muestra un perfil más cercano a corrientes autogestivas como el anarquismo o el socialismo.

\section{Conclusiones}

Las publicaciones de ambas etapas analizadas tuvieron opiniones en común y algunas diferencias. En general, buscaron el ascenso social y los productores de la prensa cumplieron en cierta forma el papel de liderazgo que buscó llevar a la población de su grupo al mejoramiento socioeconómico y cultural. La clase aparecía como una condición históricamente instituida que utilizaba las barreras e impedimentos como forma de construirse y que venía vinculada con la "raza", también construida en la desigualdad.

El grupo asociado al ejército durante el siglo XIX conoció por dentro la corporación militar y una parte de los afrouruguayos denunciaron los abusos y los impedimentos hacia ellos, mientras que otra parte de los militares -como se expresaba en La Regeneración y en El Eco del Porvenir-vivían sus experiencias como parte de su estatus digno. Estas diferencias dentro del ejército indican el apoyo o el rechazo hacia el grupo militarista y su política que gobernó el Uruguay entre 1876 y 1886. La pertenencia a los círculos militares queda para atrás en las publicaciones del siglo XX y la identificación con la clase será con el trabajo obrero.

Las influencias del contexto son claras. Los discursos afrouruguayos se fueron construyendo a medida que recogían de su realidad y del bagaje ideológico del momento los puntos para sus argumentaciones. Es notorio cómo a medida que avanza el tiempo la clase fue un tema 
analizado y sustentado teóricamente por las publicaciones. Esto habla de las lecturas que se realizaban y de la posibilidad de que algunos de los redactores se tornaran intelectuales que simpatizaron en mayor o menor medida con el movimiento obrero. Por otra parte, el sindicalismo comenzó a complejizar las teorías y políticas clasistas en el Uruguay e incluyó en su plataforma el problema del racismo, como pudo verse en la exposición de Sandalio Junco en 1928 en Montevideo.

El hecho de que las publicaciones defendiesen los intereses de la "raza" no se contraponía con defender los de la clase. Al contrario. De una forma interseccional, ambas realidades se daban juntas, pero la forma de lucha por la clase ocasionó, en el siglo XX, nuevas estrategias con otras personas que no eran afrodescendientes.

\section{BIBLIOGRAFÍA}

"Adelante". El Progresista. Montevideo. № 5, 2 de octubre de 1873. Impreso. "Agradecemos". La Propaganda (1ª época). Montevideo. N 54, 8 de octubre de 1893. Impreso.

Andrews, George R. Negros en la nación blanca: historia de los afro-uruguayos 1830-2010. Montevideo, Linardi y Risso, 2010.

A. J. F., "Antes y Ahora”. El Eco del Porvenir. Montevideo, N 3, 1 de octubre de 1901. Impreso.

Ardao, Arturo. Etapas de la inteligencia uruguaya. Montevideo, Departamento de publicaciones, Universidad de la República, 1971.

Barrán, José. Historia de la sensibilidad en el Uruguay. Montevideo, Ediciones de la Banda Oriental, 2012.

Bernand, Carmen. Negros esclavos y libres en las ciudades hispanoamericanas. Madrid, Fundación Histórica Tavera, 2001.

Cirio, Pablo. Tinta negra en el gris del ayer. Los afroporteños a través de sus periódicos entre 1873 y 1882. Buenos Aires, Teseo, 2009.

DAvit. "El derecho á vivir". La Verdad. Montevideo, № 8, 25 de noviembre de 1911. Impreso. . "La Solidaridad". La Verdad. Montevideo, N 14, 25 de enero de 1912. Impreso. 
“De Luis Ariquistain”. La Vanguardia. Montevideo, $N^{\circ}$ 12, 30 de junio de 1928. Impreso.

DíAz, CÉSAR. "Los negros porteños también hicieron periodismo". Revista de Historia Bonaerense, $\mathrm{N}^{\circ} 16,1998$, pp. 13-15.

“Doctor Crisóstomo Díaz”. La Regeneración. Montevideo, № 8, marzo de 1885. Impreso.

“Duodécima sesión”. El Trabajador Latinoamericano. Montevideo, 1829 mayo de 1929. Impreso.

“El doctor don Plácido Ellauri". La Propaganda (1ª época). Montevideo, $\mathrm{N}^{\circ}$ 9, 29 de octubre de 1893. Impreso.

"El Señor Francisco Rondeau". La Propaganda (1ª época). Montevideo, $\mathrm{N}^{\circ}$ 64, 18 de noviembre de 1894. Impreso.

Frega, Ana, Karla Chagas, Óscar Montaño y Natalia Stalla. "Breve historia de los afrodescendientes en el Uruguay". Población afrodescendiente y desigualdades étnico-raciales en Uruguay, Lucía Scuro Somma (coord.), Montevideo, PNUD, 2008, pp. 5-126.

Frega, Ana. "'La patria me hizo libre': aproximación a la condición de los esclavos durante las guerras de independencia en la Banda Oriental". "Negros de la Patria". Los afrodescendientes en las luchas por la independencia en el antiguo Virreinato del Río de la Plata, Silvia Mallo e Ignacio Telesca, Buenos Aires, SB, 2010, pp. 171-186.

García Martínez, Mónica. "Autodesignaciones de las y los afrouruguayos en su prensa (1872-1952)". Intellèctus, $\mathrm{N}^{\circ}$ 1, 2018, pp. 1-27. . "La noción de 'raza' entre intelectuales afrorrioplatenses", Encuentros Latinoamericanos (2a. época). Montevideo, Centro de Estudios Latinoamericanos, vol. 3, $\mathrm{N}^{\circ}$ 2, julio-diciembre de 2018, pp. 165-194.

Goldman, Gustavo. El espacio afro-rioplatense: clubes de afro-descendientes bonaerenses y montevideanos en el último tercio del siglo XIX. Tesis de maestría en Historia Rioplatense, Facultad de Humanidades y Ciencias de la Educación, Universidad de la República, 2015.

Herrera y Thode, Daniel. “'El canillita' como eslabón principal en las empresas periodísticas”. La Vanguardia. Montevideo, $\mathrm{N}^{\circ} 1,15$ de enero de 1928. Impreso. 
"Instrucción I". La Propaganda (1ª época). Montevideo, Nº 39, 27 de mayo de 1894. Impreso.

"Igualdad ante la ley". El Progresista. Montevideo, $\mathrm{N}^{\circ} 3,18$ de septiembre de 1873. Impreso.

Junco, Sandalio. "El Problema de la Raza Negra y el Movimiento Proletario". Bajo la bandera de la C.S.L.A.: resoluciones y documentos varios del Congreso Constituyente de la Confederación Sindical Latino Americana efectuado en Montevideo en Mayo de 1929, Montevideo, Imprenta La Linotipo, 1930, pp. 160-181.

"Las escuelas de campaña". El Progresista. Montevideo, № 6, 9 de octubre de 1873. Impreso.

"Los derechos". El Progresista. Montevideo, N 4, 25 de septiembre de 1873. Impreso.

Lukács, Georg. Historia y conciencia de clase. La Habana, Editorial de Ciencias Sociales, 1970.

Mariátegui, José Carlos. "El problema indígena”. El Trabajador Latinoamericano. Montevideo, 15 de agosto de 1929. Impreso.

Melgar Bao, Ricardo. El movimiento obrero latinoamericano II. Ciudad de México, Conaculta, 1988.

Méndez Vives, Enrique. El Uruguay de la modernización (1876-1904). Montevideo, Ediciones de la Banda Oriental, 1975.

Muñoz, Pascual. La primera huelga general en el Uruguay. 23 de mayo 1911. Montevideo, La Turba Ediciones, 2011.

Nahum, Benjamín. Manual de historia del Uruguay: 1830-1903. Tomo I. Montevideo, Ediciones de la Banda Oriental, 1996.

"Noticias". El Eco del Porvenir. Montevideo, N 3, 1 de octubre de 1901. Impreso.

"No es obra de romanos". La Regeneración. Montevideo, N 3, 28 de diciembre de 1884. Impreso.

"Nuestro candidato". La Conservación. Montevideo, N 15, 10 de noviembre de 1872. Impreso.

"Panamericanismo de pega". La Vanguardia. Montevideo, N², 30 de enero de 1928. Impreso.

"Realización del ideal". La Vanguardia. Montevideo, $\mathrm{N}^{\circ}$ 1, 15 de enero de 1928. Impreso. 
Rosal, Miguel. "La religiosidad católica de los afrodescendientes de Buenos Aires (siglos XVIII-XIX)". Hispania Sacra, N 60, 2008, pp. 597-633.

Rama, Carlos. Historia del movimiento obrero y social latinoamericano contemporáneo. Barcelona, Laia, 1976.

Tarcus, Horacio. "The First International in Latin America". "Arise Ye Wretched of the Earth": The First International in a Global Perspective, Fabrice Bensimon, Quentin Deluermoz y Jeanne Moisand, Boston, Brill, 2018, pp. 253-269.

“Undécima sesión”. El Trabajador Latinoamericano. Montevideo, 18-29 de mayo de 1929. Impreso.

Zubillaga, Carlos y Jorge Balbis. "Sindicalismo y sistema político en Uruguay. ¿Integración o confrontación? (1875-1905)”. Historias. Revista de la Dirección de Estudios Históricos, $\mathrm{N}^{\circ} 23$, octubre-marzo de 1990, pp. 141-158.

Zum Felde, Alberto. Proceso histórico del Uruguay. Montevideo, Arca, 1967.

Recepción: 19-10-20

Aceptación: 04-01-21 